\title{
EUROPA Y LA CREACIÓN DE LOS MODELOS "CÉLTICOS". EL ORIGEN DEL PARADIGMA ÉTNICO-CULTURAL
}

\author{
EUROPE AND THE CONSTRUCTION OF “CELTIC” MODELS. THE ORIGINS \\ OF ETHNIC-CULTURAL PARADIGM
}

ÓSCAR LÓPEZ JIMÉNEZ (*)

\begin{abstract}
RESUMEN
La realidad arqueológica de Europa durante los siglos XIX al XX marcó de forma definitiva el panorama actual de la investigación sobre el mundo céltico. Las grandes teorías imperialistas, replicando modelos germánicos, dieron lugar a un concepto de las sociedades antiguas que trascendía más allá de lo histórico. El paradigma étnico-cultural, fruto de estos momentos, respondía a una concepción del mundo y la sociedad determinista y claramente racista, que pese a haber perdido su sentido hoy, todavía se encuentra soterrado en algunas formas de hacer Arqueología. Cada país vivió esta etapa de cambios sociales de forma diferente y su actividad académica así lo reflejó. En España, la compleja situación europea dejó una profunda huella de la que todavía hoy existen claras evidencias en la investigación prehistórica en general y céltica en particular.
\end{abstract}

\begin{abstract}
The particular archaeological reality in Europe during 19th and 20th centuries was the basis of modern Celtic studies. The imperialistic theories, which reproduced Germanic models, introduced a racist concept about the ancient societies and their social structures. The ethnic-cultural paradigm, created in these times, was part of a racist and deterministic world conception, and is present even nowadays. Each country had a different way to live this time of social changes and the intellectual activity was an image of it. In Spain the races of the European situation are still visible at the present day.
\end{abstract}

(*) Dpto. de Historia Antigua y Arqueología. Instituto de Historia. CSIC. Duque de Medinaceli, 6. 28014 Madrid.

Este artículo fue remitido en su versión final el 25-XI-2000. Se ha realizado dentro del proyecto "Paisajes Antiguos en la Península Ibérica: teoría y práctica de la Arqueología del Paisaje" (PB97-1129 de la DGICYT).
Palabras clave: Historia de la arqueología. Celtismo. Arqueología y nacionalismo. II Edad del Hierro.

Key words: History of archaeology. Celticism. Archaeology and Nationalism. $2^{\text {nd }}$ Iron Age.

\section{INTRODUCCIÓN}

La intención de éste trabajo es presentar una visión general de la formación de las "arqueologías célticas" en los tres países europeos origen de las principales corrientes teóricas reinantes en la $\mathrm{Ar}$ queología europea hasta nuestros días. Sus planteamientos y presupuestos, pese a haber sufrido numerosas transformaciones, todavía son rastreables en muchos postulados de investigación actuales, herencia de aquel momento.

Muchos fueron los autores que generaron esas teorías y modelos, pero aquí me referiré sólo a aquellos más relevantes por su trascendencia, siguiendo a través de sus obras el análisis de los postulados generales que definen cada caso. Es cierto que el tema es de gran amplitud y los autores que participaron en su formación muchos, así como la realidad de la academia muy variada. Es necesario en este caso, por lo reducido del espacio y lo general del planteamiento, reducir y sintetizar al máximo, mostrando panoramas generales y eligiendo referentes específicos. Soy consciente, sin embargo, de la magnitud del tema y lo sesgado de la visión, asumiendo que las líneas elegidas como referentes son válidas para emitir un juicio general con una base sólida.

$\mathrm{Al}$ abordar este tema hay varios elementos que son claves para dar la justa dimensión de su interpretación. Uno de ellos será la definición de "ar- 
queólogo" que se estaba dando hacia la segunda mitad del siglo XIX y principios del XX. En este grupo entraban principalmente filólogos, filósofos, anticuarios, historiadores del Arte o aficionados eruditos que realizaban su labor de reconstrucción del pasado de forma muy personal. Esta definición se irá matizando con el paso del tiempo y no será hasta comienzos de los años 30 que se dé una dimensión moderna al término. Todos estos arqueólogos estarán insertos en un tejido social, político y personal que también es decisivo al interpretar muchas de las razones de sus trabajos.

Los casos más próximos a nosotros serán los de Francia, referente de laArqueología del celtismo, y Alemania, cuyos planteamientos teóricos serán importados y articulados sobre la realidad de nuestro país. El caso inglés será diferente, y no tendremos una relación con él de forma relevante hasta muy entrado el siglo XX. Su tradición académica se encuentra alejada de los círculos de influencia en España y sus contactos serán pocos y de índole estrictamente personal.

El celtismo europeo será decisivo en la creación de los conceptos "cultura" y procesos de "invasión" y "difusión" venidos de Centroeuropa y que, hoy todavía, subyacen en muchas interpretaciones. Elementos asimilados inconscientemente, fijados de forma subliminal y aplicados a los pueblos de la antigüedad, que forman parte de su carácter, modo de vida, etc., metidos todos los pueblos "bárbaros" en el mismo saco de los "auténticos", "naturales", etc.

Uno de los grandes pilares de la interpretación de lo céltico será la conformación de su estructura social y política, dentro de un marco europeísta. Estas imágenes de la antigüedad cristalizan a finales del siglo XIX, pero son fruto de, principalmente, esquemas lingüísticos montados sobre conceptos complejos como los de etnia o cultura y desarrollados en paralelo a otros ejemplos como los de la Irlanda altomedieval. Así se generan algunos de los modelos que más fijos quedarán en la mente de los arqueólogos y subyacerán en los escritos de todos en aquellos años.

\section{EL PANORAMA EUROPEO}

El continente europeo en el siglo XIX se convulsiona por las tensiones sociopolíticas, crisis producidas por los cambios sociales que generarán numerosas revoluciones a lo largo de este siglo y marcarán los acontecimientos del siguiente. El auge de los nacionalismos regionales se convertirá en imperialismo y colonialismo en las políticas estatales, haciendo prevalecer a algunas naciones sobre otras y creando bloques con áreas de influencia muy marcada. Nacerán así las academias y las corrientes ideológicas "promocionadas" o alineadas con las políticas nacionales, y con estas, las dos grandes corrientes ideológicas básicas que marcarán el siglo, la anglosajona y la germánica. De ellas partirán dos líneas claras de hacerArqueología.

Es en este momento en el que se producirá el tránsito lento pero revolucionario desde el anticuarismo hacia la Arqueología como disciplina, generando una metodología, asimilando técnicas de otros campos, y desarrollando teoría aplicada. Este transformación estará protagonizada en el mundo anglosajón por hombres como Lubbock, Pitt-Rivers, V. G. Childe, Spencer, Taylor o Morgan, y deudores de los planteamientos del darwinismo. Por otro lado, la escuela franco-alemana avanzaba combinando estudios de filología, lingüística, etnología y una base de anticuaristas y coleccionistas que van dando paso a profesionales que trabajarán en museos y universidades, desarrollando método y técnica, así como un marco teórico explicativo que será el difusionismo, del cual Oscar Montelius será el máximo exponente. De aquí nacerá la Prehistoria como disciplina, dando primacía al periodo temporal como referente y dejando el término Arqueología como elemento de contenido más técnico.

Uno de los pilares de esta arqueología vendrá dado por la tradición de estudios en Francia y la generación de la teoría del estado "céltico" o imperio "céltico", cuyo articulador y sistematizador será d'Arbois de Juvainville. De él provendrán numerosas asunciones sobre el carácter de los pueblos célticos, extraídas de las fuentes referidas al mundo bárbaro prerromano y de la lingüística (Fick, principalmente). Pero también será un transmisor del paradigma étnico-cultural, el cual tomará como esquema de articulación y, buscando un modelo de celtismo adecuado, argumentará sobre la estructura de las sociedades protocristianas altomedievales de Irlanda, extrapolando el modelo en el tiempo y el espacio al caso galo, generalizado como "celta". Este argumento colocaría a la Galia como primer articulador de una Europa unida, la primera "comunidad europea" bajo el esplendor del imperio celta, basado en una etnia común con unas raíces culturales comunes y una diversidad de expresiones de esta cultura.

T. P., 58, n. ${ }^{\circ} 2,2001$ 


\section{EUROPA SIGLOS. XIX/XX}

Nacionalismo / Imperialismo /Colonialismo.

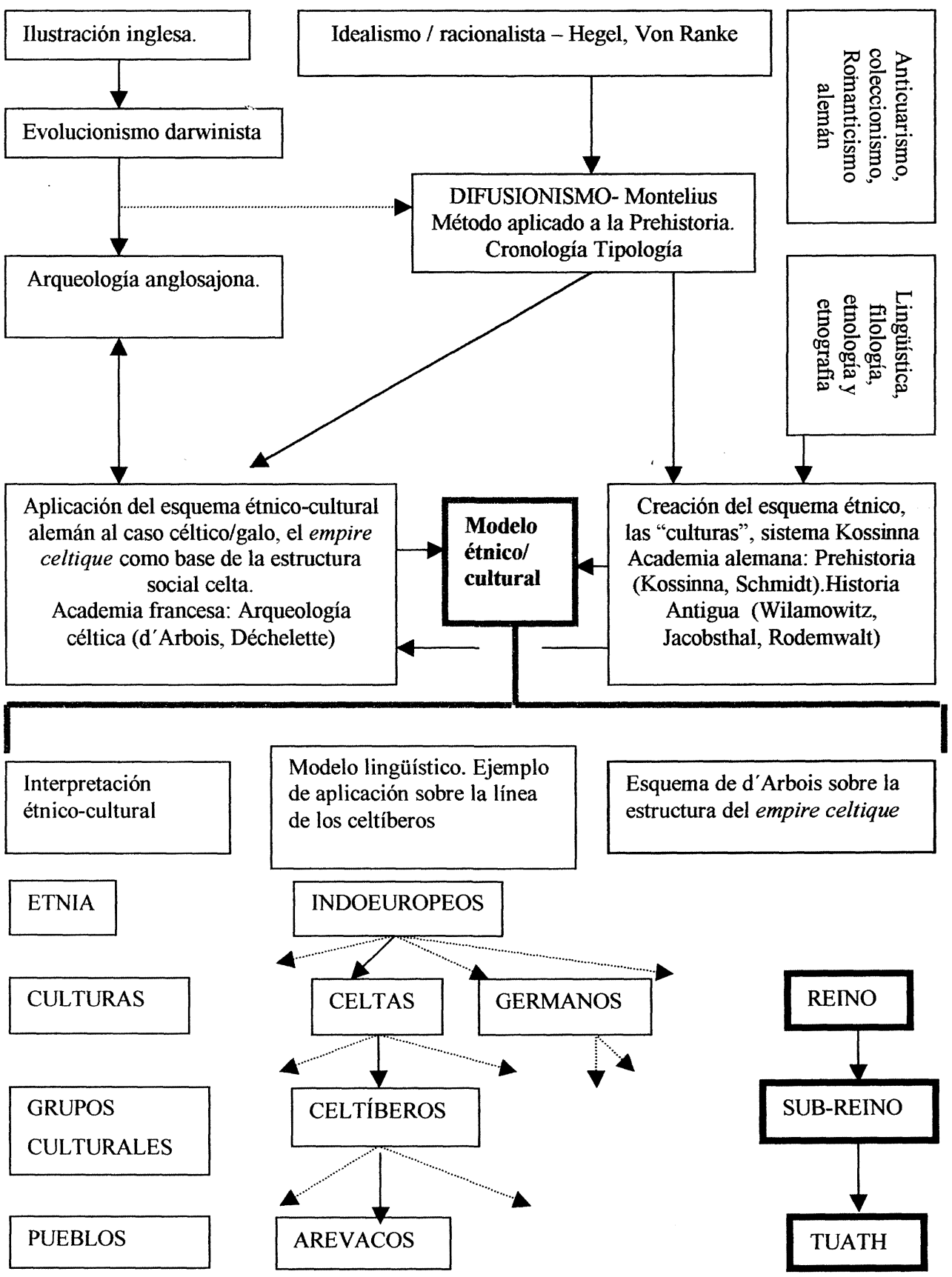

Tab. 1. Este esquema ejemplifica cómo se puede transformar un modelo teórico de origen primordialmente lingüístico a casos muy concretos o generales, según se quiera, encontrando los elementos necesarios. Este sería el caso de la interpretación de d'Arbois (1981 [1912]) y sus repercusiones hasta bien entrado el siglo XX, cuando todavía se explicaba el fenómeno de la España "céltica" asociándola con términos como "indogermanización". Aquí vemos cómo, por ejemplo, se aplicaría al caso de los celtíberos, y más concretamente a los arévacos. La estructura del sistema no tiene sentido fuera de su contexto social, cultural y académico, integrándose en una dinámica europea mucho mayor. 
La Arqueología en Europa durante los siglos XIX y XX:

El paso del anticuarismo al procedimiento arqueológico fue gradual y ajustado al retraso con el que los diferentes Estados institucionalizaban unos estudios que les parecían de utilidad. Podemos dividir claramente dos campos y vías de desarrollo independiente (Trigger, 1992: 77), ambos muy bien delimitados tanto temporal como geográfica y políticamente.

El primero de ellos iniciado en 1859 con la publicación del Origen de las especies supone un cambio radical procedente principalmente del Reino Unido y Francia, afectando a los estudios de Paleolítico y del origen del hombre y centrados más en el campo de las Ciencias Naturales.

Pero el proceso más interesante en este caso sería el iniciado en la tradición histórica nórdica, en un mundo germano-escandinavo bastante homogéneo, a finales del siglo XVIII y principios del XIX. Fue la necesidad de crear una cronología relativa factible para trabajar con los materiales arqueológicos lo que propició el desarrollo de las tipologías.

En el campo de los estudios célticos no existía una comunidad de arqueólogos "especialistas" como pasaba con el estudio del Paleolítico, que se dedicara exclusiva o por lo menos principalmente al tema. Lingüistas o aficionados con un gran conocimiento erudito realizaron ciertos estudios sobre ellos basándose en los textos clásicos. Sin embargo podemos distinguir claramente dos formas muy diferentes de tratar la cuestión céltica, procedente de dos tradiciones independientes que replican el modelo de bloques políticos que apuntábamos anteriormente.

Por una parte los estudios filológicos, más centrados en el mundo Indoeuropeo que corría a cargo de lingüistas alemanes, franceses o escandinavos, muy descriptivos y centrados en las fuentes clásicas, la Numismática y la Epigrafía. Posidonio, Estrabón, Julio Cesar, Diodoro o Tácito son citados miles de veces durante los primeros intentos de explicar la variabilidad lingüística y étnica de Europa.

A este interés se sumarán los hallazgos que desde la primera mitad del XIX se vinieron sucediendo en la Europa Central, despertando gran interés entre los estudiosos de la antigüedad y los aficionados con medios para excavar (Ruiz Zapatero, 1997: 26). Algunos de estos primeros hallazgos serían las tumbas del Rhin, conocidas en su mayoría entre 1830 y 1840 , pero las más famosas e influyentes serán las de Hallstatt (1848) y La Tène (1856), y para el nacionalismo francés la excavación deAlesia (1860).

Los nuevos descubrimientos y la revalorización de los estudios sobre la Edad del Hierro cristalizaron en el establecimiento, por Hildebrand en 1872, de los periodos de Hallstatt para el Bronce y la I Edad del Hierro y La Tène para la II Edad del Hierro. Su aportación será la base de otras grandes obras de síntesis como las tradicionales periodizaciones que surgen a principios de siglo. En este sentido son de obligado referente la obra de Reinecke (1902, 1911) o la de Déchelette (1908-10).

En cuanto a laArqueología de los celtas, durante el siglo XIX ya se había intentado trazar los patrones de distribución de algunos elementos identificatorios de lo que se comenzaban a llamar "culturas", como por ejemplo muestra el trabajo de Evans (1850) en el campo de la numismática y que será una guía importante para otros posteriores (Daniel, 1950: 303-305).

Para el caso céltico los hallazgos de LaTène eran los más firmemente identificados como celtas, tomando rápidamente un status de "cultura arqueológica" más que de estadio evolutivo. Este proceso se reafirmará y acelerará con las aportaciones de Mortillet (1870) al interpretar los elementos de LaTène del norte de Italia como restos de una invasión céltica documentada históricamente sobre esos territorios (Daniel, 1950:11).

A partir de aquí laArqueología céltica se integra en el proceso difusionista y los investigadores buscarán paralelos por doquier con todos aquellos elementos que cronológica y tipológicamente puedan asimilarse. De esta política surgen asociaciones como la de los llamados "campos de urnas tardíos" del sur de Inglaterra a los pueblos belgas (Evans, 1890) apoyándose en un texto de Cesar del año 54 a. C.

En la tradición anglosajona también existe una línea de estudios célticos muy temprana. Esos estudios, muy de moda hoy por la controversia actual sobre la identidad y etnicidad celta, han sido analizados a fondo por investigadores de renombre (Collis, 1997, James, 1999), ya que la situación actual del celtismo en Inglaterra no se puede desligar de los avatares historiográficos, marcando claramente la problemática actual (López Jiménez, 1999).

El comienzo de la tradición histórica céltica en Gran Bretaña está íntimamente asociado al caso francés y se puede decir que comienza con el trabajo

T. P., 58, n. ${ }^{\circ} 2,2001$ 
del monje bretón Paul-Yves Pezron Antiquité de la nation, et de langue des Celtes, autrement appellez Gaulois (1703). Si bien es cierto que existe una obra anterior de un escocés llamado Buchanan (1582) (Collis, 1997) donde aparece por primera vez la asunción de los britones como descendientes de celtas, no es hasta 1707, con el libro de Lhuyd Archaelogia Britannica, cuando se definen las bases de la celticidad británica. Impresionado por la obra de Pezron, Lhuyd escribe un tratado que supone un hito en el estudio de la lingüística y monumentos célticos en Gran Bretaña.

Durante el siglo XIX el evolucionismo arraigó fuertemente en ciertos círculos académicos determinando una visión de las sociedades primitivas y su desarrollo. Esta corriente de pensamiento caló profundamente en el mundo anglosajón, teniendo un rápido salto a la antropología norteamericana. Sin embargo no consiguió tomar un papel predominante en el pensamiento centroeuropeo (aunque por supuesto existió y con carácter propio) y su interpretación de la Historia. Algunos investigadores no se separaron del pensamiento tradicional derivado de los paradigmas de la Ilustración, principalmente en el área escandinava, y los que asumieron ciertos elementos evolucionistas los incorporaron al difusionismo que asentó con fuerza sus teorías explicativas sobre los procesos por los cuales el ser humano se encontraba donde se encontraba y justificaba igualmente la primacía de ciertas zonas y pueblos sobre otros.

En efecto, los estudios desarrollados a lo largo del siglo XVIII sobre las "sociedades primitivas", basados en la observación del nivel tecnológico y los medios de subsistencia, produjeron la invención de las llamadas "sociedades simples" (Stocking, 1987: 144-185). Se producen también en este momento algunas explicaciones por parte de estos pensadores ilustrados del XVIII, destacando principalmente algunos de la academia escocesa, que especulaban sobre el proceso por el cual se producía el progreso humano.

Sin embargo, durante el auge del evolucionismo a lo largo del siglo XIX, estas ideas fueron reconvertidas, emergiendo una teoría social y antropológica paralela a los planteamientos evolucionistas de Darwin y Huxley.

Numerosos investigadores participaron de este movimiento, entre ellos Spencer, Morgan, Taylor, Main, Bachofen, McLennan, o a los arqueólogos Lubbock o Pitt-Rivers, como exponentes de esta corriente, la más importante en el ámbito anglo- sajón pero difundida de forma muy diluida entre la Arqueología centroeuropea.

Como muy bien señala Trigger (1992: 147) fueron estos mismos autores los que, como muchos otros darwinistas, comenzaron a abandonar los planteamientos ilustrados de unidad e igualdad y comienzan a tratar a los pueblos nativos de las colonias como biológicamente inferiores a los europeos. Este cambio, producido principalmente por la presión de las clases acomodadas y las burguesías desde 1860 se incrementará durante los años 80, tendiendo a desechar las doctrinas del progreso y a concebir a las sociedades como resistentes al cambio, en contra de los planteamientos de la Ilustración.

Por otra parte, además del planteamiento evolucionista, la segunda vía de desarrollo será la marcada por el tránsito hacia el difusionismo. Su sistematización fue gradual y en buena parte tomando como punto de partida ciertas posturas evolucionistas. El auge de los nacionalismos de finales del siglo XIX traía consigo una serie de preceptos étnicos, culturales, biológicos e históricos que fomentaban y justificaban la separación entre las naciones y su coherencia interna. Se fomentaba la unidad nacional argumentando que sus miembros son biológicamente diferentes y que su patrimonio biológico es común (nacional), determinando un comportamiento y cultura racial cuyo hecho diferencial es inmutable.

El difusionismo aparece entre el muy potenciado campo de la antropología y la etnología en principio (área muy desarrollada por las potencias coloniales) y su máximo exponente en esta disciplina será Friedrich Ratzel (1896-1898).

El evolucionismo dio paso en muchos lugares a un hiperdifusionismo cuyos presupuestos se basaban en tres puntos básicos (Trigger, 1992: 148): 1) Que para la mayoría de los seres humanos el estado primitivo es el natural y que si no fuera por las clases gobernantes tenderían a retornar a su estado salvaje. 2) Que los salvajes son incapaces de inventar. 3) Que el desarrollo de la civilización es un accidente y que la religión es un factor básico para la promoción y extensión del proceso civilizador.

El interés por la distribución geográfica tanto de los hallazgos arqueológicos como de la recreación de los datos de las fuentes clásicas, así como el gran desarrollo de la cronología comparada hizo derivar a la Arqueología de aquel momento hacia una recreación principalmente de los periodos del Bronce y Hierro en Europa. 
Este cambio y la presentación de la aplicación de los postulados difusionistas, así como de una cronología bien desarrollada sucederá con la aparición de los trabajos del investigador sueco Gustav Oscar Montelius.

Montelius participó de los intereses y planteamientos de Thomsen y Worsaae entendiendo muy bien lo que Thomsen intentaba hacer con su sistema, convirtiéndose en el primer sistematizador de la prehistoria europea y adquiriendo una visión de conjunto como nadie había conseguido hasta el momento.

Gracias a estos conocimientos pudo construir, sobre la base del sistema de Thomsen, un método de datación tipológica mucho más ajustado y completo, intentando no sólo conseguir series cronológicas, sino determinar qué relaciones existían entre unos objetos y otros, y entre los grupos humanos que los produjeron.

El método ideado para realizar esta tarea contemplaba recoger los elementos procedentes de conjuntos cerrados, lo que le permitiría determinar cuáles de ellos estaban relacionados, y correlacionar así mediante el análisis formal y decorativo toda una serie de cronologías que había antes delimitado por regiones (Renfrew, 1973: 36 - 37).

Al plantearse el origen de la cultura occidental, la influencia de los presupuestos manejados por Ratzel y quizá también por el hiperdifusionista Elliot Smith, le llevaron a establecer un modelo, siguiendo su cronología, en el que se podía seguir la pista de los orígenes del desarrollo cultural en Europa hasta el Próximo Oriente (momento desde el cual se convierte en el iniciador de la escuela llamada de ex Oriente lux).

La influencia en otros investigadores y formas de entender la prehistoria fue clara, como atestigua la obra de Salomón Reinach Le Mirage Oriental (1893), en la que aunque con ciertas oposiciones se asume el orientalismo y la difusión como teoría explicativa.

Los aportes de Montelius serán decisivos en autores como V.G. Childe, Kossinna, Evans, y en la Historiografía española a donde llegarán como valores asumidos e incuestionables y que todavía hoy se mantienen en muchos casos soterrados en el discurso arqueológico.

Por lo tanto, el panorama académico se dividía básicamente en dos formas de entender las sociedades antiguas, la evolucionista, con todas sus variantes, de carácter más biológico de fondo, y la difusionista, nacida desde el historicismo idealista alemán.
Estas dos tendencias no serán impermeables la una a la otra, aunque sus influencias mutuas no son grandes sí se pueden apreciar, principalmente en los influjos evolucionistas en autores del historicismo.

\section{EL CASOALEMÁN}

La tradición académica alemana se construyó sobre los valores nacionales, un fuerte sentido patriótico que incluía unos presupuestos raciales muy estrictos y un método enciclopédico lleno de afán sistematizador. La producción arqueológica se encontraba casi monopolizada por los filólogos, cuyos planteamientos difusionistas sobre el proceso de inserción lingüística eran inferidos no sólo en el ámbito de las sociedades antiguas, sino dotados de contenido también racial y étnico.

Este ambiente intelectual, marcado por los postulados de la filosofía hegeliana y del idealismo alemán, principalmente representado en Historia por Von Ranke, se sustenta sobre principios de desigualdad, un concepto del Estado como fin último y origen de todo bien social e incluso una gradación de los Estados del mundo por su "capacidad de evolucionar hacia la cultura".

El modelo alemán construye una identidad nacional sobre los germanos, recreando un esquema que emularán en las regiones "célticas". El caso germánico, como el céltico para el Oeste de Europa, estará apoyado en textos clásicos, principalmente Tácito (Germania) y en tradiciones populares de raíces ancestrales similares a los ciclos irlandeses. La más famosa y representativa de estas será la recopilada en losEdda. Estas leyendas tradicionales fueron la inspiración de muchos autores de la época romántica y toman cuerpo principalmente de la mano de Wagner. Basado en la más antigua copia conservada de la historia del "Cantar de los Nibelungos" (1440 - Biblioteca Estatal de Berlín), procedente de estos $E d d a$, nacerá su gran obra, la que será orgullo de la nación germana; la tetralogía de "El Anillo del Nibelungo". Esta, como muchas otras obras, entre las que cabe destacar Lohengrin, escrita en plena revolución de 1848 , se convertirán en paradigma de la literatura romántica de este siglo.

Como esta, muchas obras servían como refuerzo a los propósitos nacionalistas del romanticismo y post-romanticismo alemán. Otras menos conocidas fueron el "Cantar de Gúdrun" del siglo XIII o los recogidos en el "Códice de Ambrés" del siglo XVI.Todos ellos están llenos de leyendas de valor,

T. P., 58, n. ${ }^{\circ} 2,2001$ 
heroísmo y orgullo de una raza fuerte que predomina sobre las demás.

De esta época son las obras de Fick o Windisch que tanto predicamento tuvieron en la literatura especializada de la época. Es en estas, especialmente en la de Fick (1873), donde se aplica el referente de los arios como modelo cultural y racial asumible como base para el orgulloso y expansivo pueblo alemán. Los arios serán un espejo de valores desprendidos de términos lingüísticos supuestamente remanentes de los pueblos indogermánicos (otro término si no creado sí divulgado por él y asumido en todo Europa). Estos indogermánicos vendrían a ser lo más puro del grupo indoeuropeo como raza. Los arios procederían de una zona que Fick sitúa entre los "turanianos" y el Mar Caspio y desde allí se desplazarían hacia el Oeste debido a su carácter expansivo y belicoso, otros dos tópicos que se asumirán unidos al resto de la teoría.

Esta interpretación será seguida por otros filólogos como Schade, Brugmann, Curtius, Meyer o Kluge, y arqueólogos (historiadores del arte o de la antigüedad) tanto alemanes (Pauli, 1891) como franceses (d'Arbois, Déchelette).

Otra fuente de influencia vendrá desde las arqueologías artística y cientifista. La primera será la generada alrededor del mundo clásico, pero que no tendrá un apoyo institucional importante al dejar de lado el territorio patrio y será un tipo de arqueología colonialista bien representada, por ejemplo, por los trabajos de Winckelman. La segunda aporta el sistematismo clasificatorio escandinavo heredado de Thomsen, Worsaae y, sobre todo de Montelius. Los alemanes serán grandes clasificadores, aportando tipologías y series como la de Reinecke (1911) o Menghin (1931-1940). La representación de los evolucionistas, como ya habíamos dicho antes, en Alemania, fue bastante pobre debido al tremendo auge del difusionismo. Tan solo algunos pocos arqueólogos, como E. Haeckel, mantenían posturas en este sentido.

Todo ello va a dar como resultado, unido a la promoción cultural fomentada desde instancias oficiales, la creación de escuelas y grupos de trabajo tendenciosos pero de importancia mundial, y como figura clave de la arqueología alemana, la obra que va a marcar el fondo y la forma de la arqueología europea será la de Gustav Kossinna.

Kossinna (1858-1931) fue el primero en aplicar el concepto de "cultura arqueológica" en sus trabajos. Se formó como filósofo, asumiendo una formación de corte hegeliano, lo que terminaría marcando definitivamente sus estructuras interpretativas sobre el análisis social y cultural de los pueblos tanto actuales como históricos.

LaArqueología será un instrumento básico por medio del cual averiguar el lugar de procedencia de los pueblos indoeuropeos y más concretamente alemanes. Este patriotismo le llevó a calificar de traidora (Trigger, 1992; 158) a laArqueología Clásica, Egiptología oAsiriología y toda aquella que no sirviera para ensalzar la grandeza del pasado alemán, ya que consideraba a la Arqueología como la más "nacional" de las ciencias. Su primera obra de repercusión internacional (Kossinna, 1911) representa una reivindicación nacionalista desmesurada, pero también una renovación en la metodología, el purismo de los datos, el enfoque diacrónico y holístico, etc. Una síntesis de buena calidad y profundidad del trabajo que no llegará a España hasta Bosch Gimpera. En esta, que sería la más voluminosa de sus obras y que serviría de lienzo para una declaración de principios teórica y metodológica, encontramos ya todos los aportes novedosos, positivos y negativos de sus planteamientos. Aparecerá el interés por rastrear, en el estricto sentido arqueológico, los orígenes del pueblo germano, remontándose al mundo de la Edad del Bronce para buscar unas invasiones justificadas por el carácter invasionista y expansivo de estos pueblos y afirmar que ya estaba constituido su hecho diferencial como cultura (Kulturvolker).

Sin embargo instituyó una serie de presupuestos teóricos erróneos y que más tarde tendrían graves consecuencias. Su interés por las "culturas" en el sentido etnológico del término, acuñado ya por Tylor (1871) al que sigue en muchos aspectos, iba más allá de aportar grupos étnicos prehistóricos, sirviéndose de ellas para establecer una serie de gradaciones raciales y étnicas. Asumiría también las conclusiones del antropólogo de principios del siglo XIX Gustav Klemm, que definía en el carácter innato de las etnias dos rasgos diferenciadores, el Kulturvolker, o pueblo creativo y superior, y el $\mathrm{Na}$ turvolker, o pueblo pasivo culturalmente e inferior.

En otros escritos, como su Die Indogermanen (Kossinna, 1921) desarrolla el proceso de rastreo retrotrayéndolo a la remotaSteinzeitdel mundo indoeuropeo, para él indogermano indudablemente por influencia del trabajo de Fick (1873). Es también en este trabajo donde Kossinna comienza uno de sus procedimientos argumentales, la paleoantropología comparada, en lo que también fue un precursor.

Sin embargo su gran obra recopilatoria de las 
esencias germanas, Die deutche Vorgeschichte (eine hervorragend nationale Wissenschaft) no la llegará a ver publicada nunca, ya que saldrá en 1941, en plena guerra mundial, diez años después de su muerte.

Pese a la carga negativa que hoy podemos achacarle a su trabajo, las aportaciones de Kossinna fueron cruciales metodológica y teóricamente e introducen conceptos que han permitido la creación de un cuerpo académico en la disciplina. No fue sólo el primero en utilizar el concepto de cultura, tan familiar hoy, sino que reveló la importancia de los enfoques holísticos, donde se contemplan las culturas arqueológicas individuales de manera global y diacrónica.

El uso político de las ideas de Kossinna fue tremendo, siendo una de las bazas argumentales de los nazis en sus reivindicaciones sobre las tierras anexionables o como justificación de su supremacía en Europa.

La Prehistoria estaba ya aceptada y conformada como disciplina académica enAlemania desde principios del siglo XX, destacando los estudios de Hubert Schmidt y el propio Kossinna, quienes desarrollaron trabajos amplios sobre los pueblos del Neolítico a la Edad del Bronce, aportando gran cantidad de metodología de excavación, catalogación y técnicas tipológicas, así como análisis aplicados.

Berlín contaba, además de los profesores ya mencionados, con importantes figuras como Paul Reinecke, Otto Friedrich Gandert, o Ernest Sprockoff, lo que convirtió a la ciudad en el primer centro de investigación en Prehistoria de Alemania. Pero otras ciudades albergaban también grandes hombres de la prehistoria alemana. EnViena impartía clase Oswald Menghin, en Marburg lo hacía Gero Von Merhart, y en los museos y la Universidad de Hamburgo, Walter Matthes. Desde la Arqueología Clásica tendrá gran importancia Paul Jacobsthal, cuyos intereses tocaban también el mundo mediterráneo y sobre todo la iconografía de las producciones protohistóricas.

Oswald Menguin, recogerá elementos que producirán trabajos en el campo de la etnología, etnografía y paleo-etnología europea dentro de esta corriente. Sus trabajos dejarán, principalmente, una articulación que es deudora del método Kossinna y que aparecerá en el discurso de numerosos arqueólogos europeos, principalmente en los primeros años, en conceptos como la delimitación cultural como identidad étnica, llegando a eliminar la diversidad cultural de los pueblos prerromanos, tendien- do a homogeneizarla. Un concepto ejemplificador, directamente heredado de sus postulados será el de la "comunidad espiritual", rápidamente difundido (Almagro Basch, 1958: 42).

Esta escuela se forma sobre trabajos como los de Merhart (1936) y las aplicaciones de campo de investigadores como Jankuhn (1943), que en aquellos momentos trabaja en el yacimiento germano de Haithabu. De todos ellos y especialmente de los trabajos de Jacobsthal $(1908,1929)$, nace una sistemática preocupación por la cronología tipológica, por las redes de intercambio, las relaciones comerciales en general y su importancia como motor del "cambio cultural".

Los estudios del mundo antiguo también aportaron elementos de apoyo a los estudios célticogermánicos. Los museos con sus amplias colecciones (Berlín, Colonia, Wiesbaden, Maguncia, Bonn o Munich), el desarrollo de las disciplinas filológicas, epigráficas y numismáticas, o figuras como la del profesor Ulrich Wilamowitz - Moellendorft, filólogo clásico, maestro de numerosos arqueólogos de la época y con un gran poder político, definieron en buena medida también el rumbo de estos estudios.

Otras disciplinas, como la paleoantropología, la etnografía y la medicina forense comienzan a despuntar con fuerza y a introducirse en los estudios, principalmente de Prehistoria. Grandes profesores de estas disciplinas formaron a los prehistoriadores del momento, como Leo Frobenius, Felix Von Luschan y Von Tranwitz en Berlín, R. Martin en Munich o Wilheim Koppers en Viena.

Algunos investigadores mantuvieron ideas más alejadas del ámbito político y, aunque nunca exentos de cierta influencia kossinniana, permanecieron en los círculos académicos estrechos y poco realistas. No así, la Antropología despuntará en cuanto a la capacidad para apoyar y justificar estos postulados, apareciendo obras de gran calidad documental pero muy tendenciosa, como la magnífica recopilación de Eckart Von Sydow, Die Kunst der Naturvolker und der Vorzeit (1938), traída pronto a España aunque nunca traducida. Ejemplo perfecto de las obras del Reich, desplegará un conocimiento amplísimo sobre las culturas antiguas de los cinco continentes y sus paralelos en la Prehistoria, incluyendo numerosas fotos, y justificando la actual pirámide cultural por un hecho natural de supremacía de los individuos mejor adaptados.

En España existirá una influencia alemana muy importante desde la escuela de Madrid, a cargo de

T. P., 58, n. ${ }^{\circ} 2,2001$ 
Hugo Obermaier. Aunque sus estudios se centrarán en el mundo del Paleolítico hará referencia a las tradiciones asumidas en torno a ellas por los grandes maestros de su país, principalmente el profesor Joseph Bernhart. Con él escribió su Urgeschichte der Menschheit (1931), estando ya en su cátedra de Madrid. En esta obra, en escasamente tres páginas (de las más de 400 que tiene) se relatan la Edad del Hierro y el mundo céltico. No será sino una visión muy ortodoxa tomada de los textos clásicos, ajustada a la interpretación expansionista del difusionismo reinante y un indoeuropeismo patriótico alemán. A través de sus obras llegarán a España muchos elementos ideológicos cuya influencia se notará en todos los investigadores de la época y especialmente en algunos como Mélida o García y Bellido.

El influjo alemán vendrá a España principalmente por el contacto directo entre investigadores y el interés por una formación internacional que llevará a muchos a ampliar estudios en el país germano durante las décadas de los veinte y treinta. Los españoles van estudiar a Alemania como principal potencia en Filología, Historia oArqueología.Así, la Junta deAmpliación de Estudios mandará a multitud de investigadores en formación a Alemania durante ese periodo a estudiar con los grandes maestros alemanes como Wilamowitz-Moellendorft, Schmidt o Menghin (Díaz-Andreu, 1995, 1996).

Igualmente, algunos investigadores alemanes trabajaron en España desde principios de siglo trayendo también aires germánicos y desarrollando proyectos arqueológicos dentro de la política de colonialismo cultural emprendida en estos años por Alemania como Humboldt, Hübner o Schulten.

La alemana será, en definitiva, una escuela muy reglada, de profunda jerarquía y de la cual hemos tomado a Kossinna como punto de referencia por ser el que más ha destacado a posteriori. En efecto él será el que fije conceptos como "cultura", o "paradigma étnico", o creará la primera "arqueología de los asentamientos" (siedlungsarchäologische methode), aunando técnicas tipológicas y cartografía.

Será una escuela de prehistoriadores e historiadores de la antigüedad que observará numerosas influencias de otras disciplinas, siendo en Prehistoria en la que más claramente se vea la aplicación de nuevos métodos desde la etnología, la antropología física o la geografía. El llamado método Kossinna será seguido por numerosos maestros de la arqueología alemana, como Schmidt o Menghin, y otros extranjeros, como Childe.
En definitiva, muchos de los conceptos aportados por esta arqueología serán bases de la nuestra casi hasta nuestros días. El paradigma étnico será aplicado desde entonces como base de trabajos en España durante toda la primera mitad del siglo XX, el concepto de "cultura" sigue hoy siendo utilizado sin saber hasta qué punto tiene repercusiones éticas, ya que este concepto fue creado para responder a un esquema en el que un artefacto respondía a una "cultura", una distribución de artefactos a una región cultural, una región cultural a un grupo de asentamientos y este a un grupo étnico que era asimilable a un pueblo histórico.

\section{EL CASO FRANCÉS}

La producción de literatura especializada sobre el tema céltico en Francia fue muy amplia durante finales del XIX y principios del XX, coincidiendo con una construcción de la identidad sobre una etnicidad gala que se desarrolla en estos años. Siguiendo los pasos de una tradición académica muy desarrollada en todo lo referente a las colonias y a los estudios orientales y mediterráneos, la arqueología había desarrollado en Francia un corpus profesional amplio y una completa metodología (GranAymerich, 1998).

Desde muy temprano los monarcas y nobles franceses centraron su atención en el pasado mítico céltico como punto de partida sobre el que referenciar unos valores étnicos franceses. A mediados del siglo XIX, una vez sobrepasados los intereses por encontrar líneas comunes con los antiguos héroes troyanos o griegos, la magnificación de unos elementos con un carácter propio, una tecnología y un arte bien caracterizados, una sociedad compleja de reconocidos valores en las fuentes clásicas y, sobre todo, geográficamente establecidos en territorio francés, hicieron de la arqueología de los celtas un foco de atención académica y política.

Los galos nunca habían sido abandonados en la historiografía francesa desde que fueran convertidos en el Renacimiento en paradigma de valor, fuerza y fiereza, replicando los adjetivos tantas veces relatados por los romanos en la descripción de estos pueblos. Sin embargo retoman el protagonismo del interés de los historiadores al tiempo que en otros lugares de Europa surgen nacionalismos basados claramente en estos pueblos. Es muy representativo el caso irlandés, el cual, bajo las presiones políticas británicas, desarrolla un corpus argu- 
mental nacional céltico que influirá y, a su vez, será influido por los historiadores franceses. Los ciclos mitológicos, los primeros escritos de las sociedades protocristianas de los siglos V al VIII d. C. y las leyendas tradicionales tanto irlandesas como escocesas y galesas proporcionaron una buena base de estudio para los celtistas del momento. El mejor ejemplo de esto será d'Arbois de Jubainville (1871; 1889), el primer gran sistematizador de una "Arqueología erudita" sobre los celtas más allá de las fronteras francesas, escribiendo sobre las etnias antiguas de Europa y sobre sociedades como las irlandesas o los grupos celtas en España.

Henri d'Arbois de Jubainville fue uno de los padres de la protohistoria actual. Estudió entre otros lugares en el Collège Royal du Nancy, donde fue discípulo del profesor Vincent Joguet en sus estudios de Historia.

La obra clave del pensamiento de d'Arbois fue publicada en 1889 y se tituló Les Premiers Habitants de l'Europe. En ella hace una revisión profunda y con una argumentación de gran densidad de cómo, cuándo y por qué aparecen en Europa los diferentes grupos étnicos, comenzando con los indoeuropeos a los que relaciona claramente con los celtas. Sus ideas quedarán fijadas en esta obra y se repetirán en posteriores publicaciones con mínimas variaciones (1902). La línea discursiva tendrá una clara intencionalidad, la de caracterizar y contextualizar a los galos (celtas en general) dentro del panorama europeo, analizando sus orígenes, su "civilización" y sobre todo sus características étnicas, enlazándolas con las de los pueblos "arios" como mejor y más firme y nobiliario antecedente étnico. Los pueblos indoeuropeos son descritos con gran detalle y una amplia base filológica que, en aquel momento, es el $80 \%$ del conocimiento que se tenía de ellos, ya que la asimilación a restos arqueológicos era demasiado endeble.

D'Arbois fijará su origen hacia el 2500 a. C. en la zona del Oriente Medio, siendo para él los asentamientos más antiguos los de Buchara y Samarkanda, cerca de los supuestos límites con las culturas del Indo. Una de las primeras y más importantes cuestiones que remarca es la del carácter expansionista de estos pueblos, explicación de por qué se difundió la lengua por Europa y una de las asunciones más comunes al "carácter céltico". Así se justifica igualmente poder tratar las lenguas europeas como un todo cuyo nexo común será ese grupo indoeuropeo que contrasta como "cultura de referencia" con el resto de lenguas y culturas anteriores que quedarán, según d'Arbois, aculturadas por el impacto "civilizador" indoeuropeo.

El repaso lingüístico a los orígenes indoeuropeos es impresionante, recogiendo obras de filólogos, principalmente alemanes y algunos franceses. La amplísima bibliografía alemana generada en estos años sobre la cuestión indoeuropea (aria) ofrece una base sólida sobre la que argumentar ese nexo paneuropeo liderado por pre-celtas y celtas (léase alemanes y franceses) mediante referencias a numerosos autores hoy apenas conocidos y, más comúnmente, a otros como Fick (1873), Schade (1856) o F. de Saussure (1871).

D'Arbois plantea el problema de los indoeuropeos asumiendo casi al pie de la letra el trabajo de M. Fick (1873), donde caracteriza a los indoeuropeos como habitantes de la zona entre el Indo y el Mar Caspio, que ya se denominarían a sí mismos "arios" (arya), que querría decir"fiel", "entregado", pero que tendría el valor de "puro" tal y como parece explicarlo Fick.

Sobre las teorías de Fick y otros lingüistas, d'Arbois reconstruye los movimientos mediante los cuales se expandieron estas gentes por Europa, siendo los primeros (los primigenios) emigrantes los asentados tras la primera migración entre el Báltico por el Norte, el Rhin por el Oeste, el Danubio por el Sur y el Dnieper y Niemen por el Este. La frontera del Rhin es muy importante pues separa a estos de los iberos (a los cuales nombra como fronterizos), que según él serían los habitantes primeros de esta zona junto con illyrios, tracios y ligures. Estas gentes se suponen muy desarrolladas tecnológica y socialmente, ya que las raíces de las palabras analizadas contienen referentes de aquel entonces, a la agricultura, ganadería, metalurgia y estructuras sociales como la idea de "monarquía" y de "ciudad", como opuesto a extranjero.

Este sustrato dará lugar, a partir del 2000 a. C. a una gran comunidad lingüística y cultural que se desarrollará hasta dar como resultado la nación céltica (Nation Celtique), concepto que rápidamente calará en los autores del momento ávidos de megaloteorías. Esta será otra de sus principales y más trascendentes aportaciones.

Como ya dije, la referencia a los celtas a través de d'Arbois nos llega ya como esa nación gestada en los lazos comunes ario-indoeuropeos básicamente desplegados por la fachada atlántica europea. La primera cuestión que hay que asegurar es que la justificación lingüística sea fiable, con lo que realizará un completo análisis de los restos lingüísti-

T. P., 58, n. ${ }^{\circ} 2,2001$ 
cos, sobre todo de los sustantivos, adjetivos y diptongos, principalmente -ei por su conexión con los indoeuropeos en ç céltica. La importancia de estos datos lingüísticos se basa en que será a través de ellos que pueda establecer, por ejemplo con los -briga y-dûros, elementos de diferenciación étnica para adscribir ciertos pueblos, como los celtíberos, a la "nación céltica".

La base primordial para recoger las localizaciones será la obra de Desjardins, tanto en su Geographie de la Gaule d'aprés la Table de Peutinger (1883), como la Geographie Historique et Administrative de la Gaule Romaine (1871), la obra de Lognon Atlas Historique de la France (1869), y todas la referencias a fuentes clásicas empezando por César (De Bello Gallico), Ptolomeo, Estrabón, Plinio, Avieno, Apiano, Diodoro, Plutarco e incluso el Itinerario Antonino. Es interesante ver algunas obras de autores anglosajones entre ellas, como The Celts, Roman and Saxons (1844), de Thomas Wright, o The Origin and History of Irish Names and Places (1877) de P.W. Joyce; pero desde luego no podían faltar las lecturas de Mommsen.

Sin embargo, la supuesta conquista de las islas británicas será justificada siguiendo a Reinach, aunque sin citar una obra concreta suya, argumentando que su llegada tuvo que ser en época homérica $(950$ - 800 a. C.), después de la caída de la "p" intervocálica. Más bien parece que intuye una presencia celta en las islas, y sobre todo Irlanda, la "joya virgen del celtismo", que se ve apoyada por la descripción de César de los Belgas en Albión, pero que es necesario que sea anterior, aunque las fuentes no digan nada de ello, para quedar coherente con su argumentación.

El foco regente, por llamarlo de alguna forma, del celtismo europeo, su epicentro, estaría situado entre el Sena y el Loira y la parte septentrional del Garona. La expansión llegará más tarde con los belgas, sobre el texto de César, creando un estado paneuropeo.

Este concepto de "nación céltica" está ampliamente desarrollado sobre la base de la lingüística y las fuentes, describiendo multitud de aspectos de la vida como el arte de la guerra, hábitat, geografía, mobiliario, medicina, religión, etc., dándole mucha importancia siempre a las relaciones entre celtas y germanos. Esta "nación céltica" tendrá como nexo común la lengua y se habría gestado ya con los indoeuropeos de los que son directos descendientes.

Desde la Península Ibérica hasta las Islas Británicas, del norte de Italia y Grecia hasta las tierras del norte de Francia y Bélgica, se extenderían sus dominios. Durante los siglos V y IV a. C. a esa nación se le conoció un mítico rey, Ambicatus, a través de los textos de Diodoro de Halicarnaso principalmente. D'Arbois seguirá sus indicaciones para trazar el perfil del estado de los celtas que para él tendrá un carácter perfectamente estatal y expansionista:

...A l'époque de l'invasión des Celtes en Italie, le régime monarchique avait prevalu chez eux: Ambicatus, ou mieux Ambicatus était roi du Celticum... (D’Arbois, 1889: 301).

Su reino correspondería, a su entender, más a la gran céltica descrita por Diodoro y otros geógrafos griegos, que a la ...petite Celtique... (D'Arbois, 1889: 301) de Julio Cesar. Esta gran oikoumene céltica estaría motivada por sus valores intrínsecos, su lengua común y una necesidad de aliarse contra griegos, cartagineses, etruscos e ilirios. Sin embargo los celtas no pueden llevarse mal con todos sus vecinos, sobre todo porque la cercanía cultural y el tronco común crean una unión muy especial con los germanos. Entre ellos se establece una relación de respeto y de cierta buena convivencia. Estando divididos sus territorios por el Rhin, unos ocuparán la margen izquierda y los otros la derecha, pero, como aclaración por si alguien se cuestionara cuál de los dos pueblos era más preeminente añade una pequeña coletilla: ...les germains sujets des Celtes (D'Arbois, 1889: 303).

Para reconstruir la estructura de este "estado" recurrirá a un modelo bien conocido en las fuentes clásicas irlandesas de los siglos VI a VIII d. C. como son los Túath. Esta institución de carácter administrativo y geográfico según las fuentes de las primeras sociedades cristianas irlandesas (Patterson, 1994; Lucas, 1989; Kelly, 1988) sirve para extrapolar el sistema a una macroestructura europea.

La estructura estatal se justifica como representativa del mundo celta argumentando que correspondería a la de los celtas goidélicos al invadir las islas y llevar la lengua hacia el año 1000 a. C., siendo por lo tanto los ...ancêtres des Irlandais (D'Arbois, 1889: 303), y en consecuencia expondría la estructura original de estos pueblos que de otra forma no conservaríamos.

Este argumento casa muy bien con la organización social supuesta para los grupos celtas. La unidad política o Tuatha se compone por tuath (inferencia directa del modelo irlandés). Estos sobrevivirán tras el periodo normando incluso, representando espacios arraigados en la cultura y creencias 


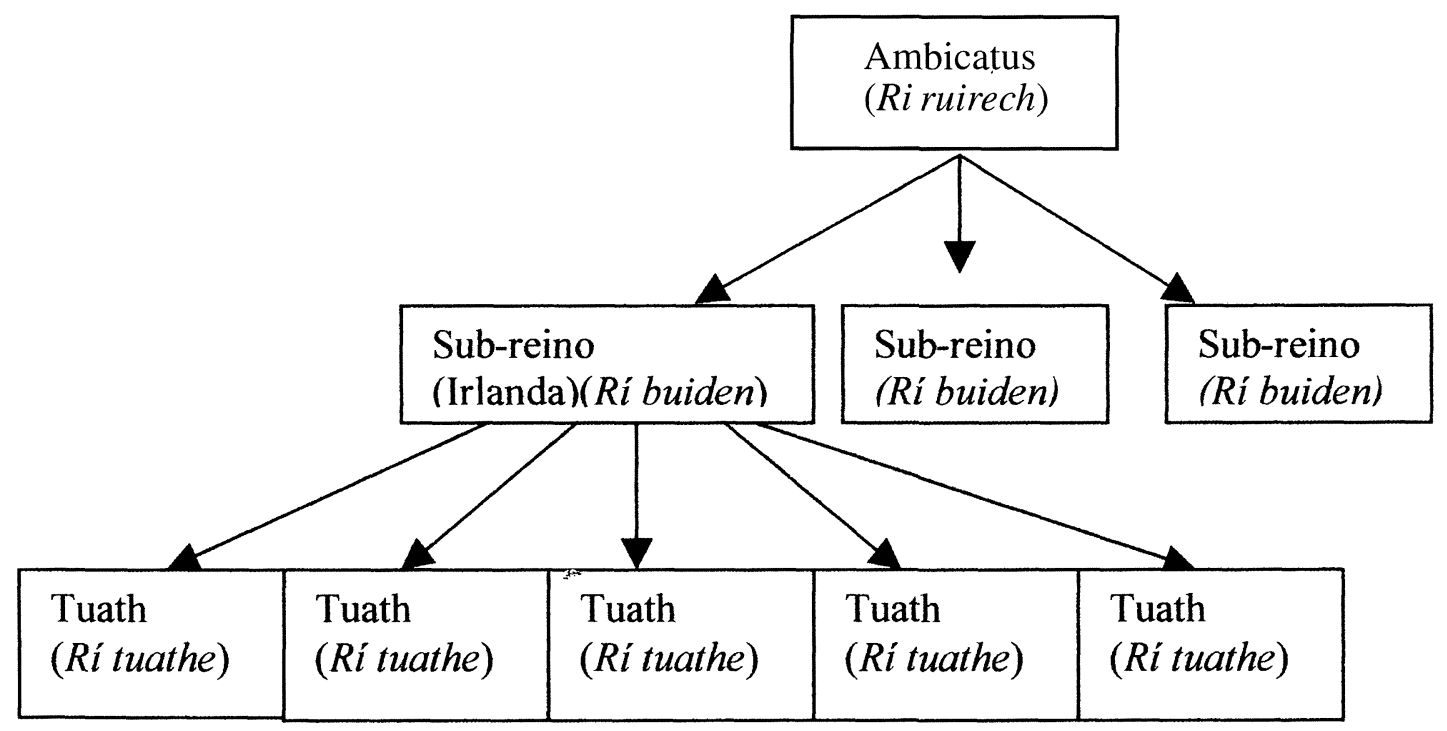

Tab. 2. La estructura de los reinos en el "estado celta" según d'Arbois y la equivalencia con las categorías de los reyes del Crith Gablach. Las estructuras de poder regionales se colocan en una estructura piramidal predeterminada para cumplir unas funciones propias de un Estado.

de la zona. Estas parcelaciones y límites políticos culturales y geográficos son recogidos en el Crith Gablach, una parte de los Uraicecht Becc o textos legales de la región sudoeste, principalmente Munster (Kelly, 1988), puestos por escrito entre los siglos V y VII d. C.

En estos textos se expone la división de los reyes en la Irlanda de las primeras comunidades cristianas (siglos IV, V o VI d. C.) y sus categorías. De ahí salen las asociaciones de d'Arbois. En lo más alto del poder estarían el Rí ruirech, que sería un rey con reyes vasallos, luego el Rí buiden, que dominaría varios tuath, y por último los Rí tuathe, o reyes de un tuath (Patterson, 1994: 196-197). Igualmente estos peldaños de la estructura piramidal se regirían por asambleas a diferentes niveles, siguiendo el estilo relatado por Tácito para los germanos, de forma que aparece descrita como una especie de democracia bárbara.

Sin embargo lo que d'Arbois no tiene en cuenta es la regionalidad y especificidad de la evidencia que exponen estos textos, extrapolándola al conjunto de Europa. Pese a esto, con d'Arbois ha quedado centrada la caracterización de esos celtas que hoy consumimos y que heredamos básicamente de esta creación de fines del siglo XIX. Esta reconstrucción se basará en dos puntos básicos, la inferencia de la lingüística al campo de lo social y la ordenación de los testimonios de las fuentes tomados de forma bastante arbitraria.
El concepto de los celtas o galos, aunque generalmente d'Arbois se refiere a ellos como celtas y sólo en ocasiones concretas como galos (D'Arbois, 1872: 457), definido en sus obras, marcará claramente una época en la historiografía y sus obras serán muy leídas por los estudiosos de toda Europa, especialmente en España.

D’Arbois aporta, además de una visión amplia y detallista del mundo céltico, una opción ante la interpretación hasta entonces más aceptada, que había sido la de Thierry (1828) basándose en la lectura de César y que no coincidía con las áreas nucleares de La Tène y los celtas históricos (Pare, 1991). Sus planteamientos tendrán mucha importancia en autores como Reinach (1892) que asumirá un panorama básicamente similar pero haciendo hincapié en la estructura de "estado" formado que implica el término "celta" como concepto étnico, cultural y político.

Los estudios sobre los galos y celtas se sucedían desde mediados del siglo XIX (Belloguet, 1858), preparando una entrada al siglo XX repleta de estudios de las grandes regiones (Bertrand y Reinach, 1894), hipótesis sobre la forma y estructura social o costumbres según la interpretación de las fuentes y un creciente interés sobre las representaciones artísticas y los objetos característicos de esta cultura (Bertrand, 1889). Sin embargo todos estos trabajos serán recopilaciones más o menos originales de datos de fuentes y objetos, adoleciendo en cierta for-

T. P., 58, n. $^{\circ} 2,2001$ 
ma de un sistematismo y de la elaboración de una teoría de gran alcance, que será la mayor aportación de Déchelette.

Todos ellos y sus argumentos serán recogidos por él en su monumental obra de cuatro volúmenes (1911-1914), de la cual no llegó a ver publicado el último. Las circunstancias de la historia hicieron que la vida de Joseph Déchelette (1862 - 1914) no fuera demasiado larga. En sus libros segundo y tercero de esta tetralogía que compone su gran obra tratará el tema de los celtas y el sustrato precelta en Europa.

Tras de sí dejó una obra de síntesis clave sobre el conocimiento y concepto de la arqueología prehistórica, protohistórica y antigua de la época, sentando el conocimiento hasta ese momento y marca el inicio de la investigación en el siglo XX. Esto se hace más palpable en el caso de la Edad del Hierro y el mundo galo-romano, ya que fue un tema sobre el cual el autor más había trabajado.

Siguiendo a los textos clásicos y las obras de Desjardins (1883), Bertrand (1889), Reinach (1892) y principalmente d'Arbois (1889), aborda la composición étnica de las poblaciones precélticas europeas. Tal y como recogen las fuentes clásicas, haciendo referencia a pasajes de Posidonio, Eratostenes, Hecateo, Scylax, Avieno, Estrabon y Diodoro Sículo, estos pueblos serían ligures e iberos, y estarían bien caracterizados por sus costumbres y cultura material. Estos pueblos asentados desde la Edad del Bronce tendrían ya una cultura desarrollada de la cual podrían los celtas adoptar muchos elementos. Déchelette será el mayor defensor de la hipótesis de los ligures como base pre - celta, que se adoptará en la Península Ibérica con prontitud y no será desbancada hasta bien entrado el siglo XX. En este aspecto, reproduce la interpretación de d'Arbois fielmente, justificando las raíces lingüísticas mediante los estudios de Fick (1873) detallados por el mismo d'Arbois. La zona ligur se repartiría en re- giones de las cuales la mayoría estaría en Francia y en España sólo en las zonas de interior no dominadas por los iberos. Los contactos principales siempre volverán al Mediterráneo, y las principales influencias en estos pueblos serían las de Egipto, Creta o Grecia y sus restos materiales rastreables las guías para una datación cronológica comparada.

Otra de las aportaciones de Déchelette fue la consideración de la migración como algo sistemático y programado en el carácter de los pueblos celtas, constituyendo una necesidad cultural. Según las fuentes antiguas, Hecateo de Mileto, Festo Avieno o Herodoto, en un momento que coincidiría con el periodo del Hallstatt C y D, entre el 900 y el 500 a. C. se desarrollarían las primeras grandes comunidades celtas y sus movimientos por Europa. Esta datación aproximada se apoyaría también en los análisis lingüísticos, distinguiendo vagamente varios momentos que comenzarían con los nombres de $\kappa \varepsilon \lambda \tau o ́ s$ para las más antiguas referencias y de $\gamma \alpha \lambda \alpha \tau \eta ́ s$ a partir del siglo III a. C. También recoge la preocupación por delimitar las diferencias entre germanos y galos, analizando el primer texto donde aparece definida la Galia (Catón, Orígenes II, 34.) hacia mediados del siglo II a. C., en la línea de los trabajos de d'Arbois. Toma de la reciente obra de Dinan (1911) el concepto de la plena estructuración de la etnicidad celta hacia el siglo IV, apoyándose también en el mito de la "pancéltica de Ambicatus".

Los pueblos celtas para Déchelette tendrán un fuerte componente mediterráneo que no se había fomentado hasta entonces, trazando una línea de contacto desde el Mediterráneo oriental hacia Iberia y Galia, de allí con Cornualles e Irlanda (basándose en la mitología irlandesa estudiada por d'Arbois, principalmente en el Lebor Gablach) (D'Arbois, 1981), las costas del Mar del Norte y del Báltico. Defenderá la creación de un estado céltico de carácter ecléctico, remarcando las vías de comu-

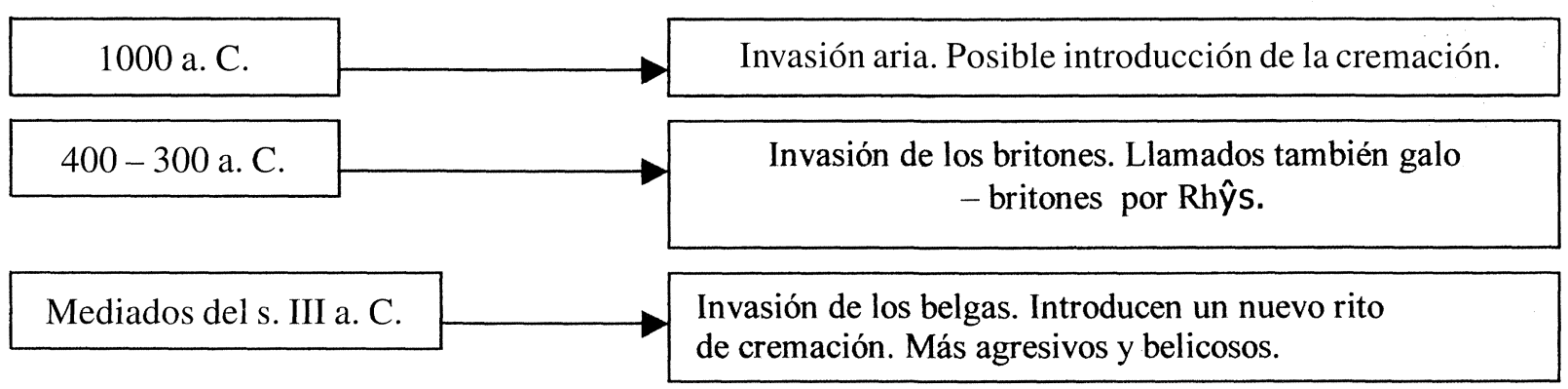

Tab. 3. Esquema de las invasiones descritas por Déchelette (1911-1914, III).

T. P., 58, n. ${ }^{\circ} 2,2001$ 
nicación y comercio y las influencias de otras culturas. Por la vía continental seguirá, unas veces con mas fidelidad y otras alterándolas, las rutas marcadas por las fuentes en el centro de Europa, que plantea que se comienzan a utilizar desde su Bronce II (hacia el 2000 a. C.). Estas rutas unirían el norte del Adriático con Escandinavia a través del Noricum, los valles del Moldava y del Elba (siguiendo a Herodoto) y por el Danubio en ambas direcciones (aunque no estrictamente como proponen el Pseudo-Scilax oAristóteles).

Esta visión de aporte cultural responde a la mayor cantidad y calidad de hallazgos que ya entonces existían y relacionaban a Centroeuropa con Etruria, Grecia y otros lugares del Mediterráneo.

Sobre esta base de pueblos del Hallstatt interrelacionados y de carácter étnico afín, se desarrolla un Estado expansionista y conquistador que en varias oleadas compondrá un imperio céltico.Aquí nace la verdadera argumentación y sistematización de la teoría de las oleadas de invasiones profundamente arraigada en la investigación hasta nuestros días. Estas oleadas se verán luego en todos los autores españoles más o menos definidas, delimitadas y asociadas con unos u otros pueblos, pero su puntal en la arqueología española será Pedro Bosch Gimpera. Más tarde, todos habrían asumido el concepto de invasión, llegando a nuestros días como simples "influjos", "aculturaciones", o "aportes de población".

Para Déchelette las invasiones serán tres, una al final del Hallstatt, otra en el siglo IV a. C. (correspondiendo con el saqueo de Roma descrito por Polibio) y las últimas en el siglo III a. C. Estas invasiones no serían sólo un impulso de bandas desorganizadas para hacer razzias, sino una política desarrollada por un "Estado" en cuya cultura la guerra tiene una importancia capital. Este Estado tendrá una caput celtici, dominada por un rey soberano. Una vez más aparecerá la figura de Ambicatus, argumentando como d'Arbois y apoyándose en el testimonio de Tito Livio sobre un rey de los Bituringos de este nombre.

Será en la primera invasión cuando se apoderen de las Islas Británicas e Irlanda, en el siglo IX a. C., argumentando para ello que, como dice Reinach

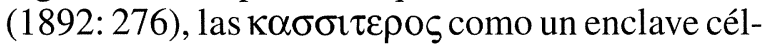
tico en la desembocadura del Rhin.

Como hemos visto, el aporte de Déchelette fue principalmente la divulgación y fijación de conceptos y teorías hasta el momento dispersas, ya que aunaba en una sola obra todo lo conocido sobre prehistoria y protohistoria del momento, y muchas generaciones han seguido usando su manual. Ideas que se encontraban ya en autores anteriores fueron desarrolladas, retocadas o simplemente transmitidas tal cual, para hacer mella en el pensamiento arqueológico de toda Europa. En el caso estrictamente español, fue conocido de forma general en los años veinte, siendo cita obligada para los arqueólogos desde aquel momento y, todavía hoy, una importante obra de consulta.

La influencia de Déchelette hizo replantearse a Georges Dottin (1906) su primera obra sobre la céltica. Así se rehace su obra más conocida y consultada en España que se vuelve a editar en 1915 con un título similar, Manuel pour servir a l'étude de l'Antiquité Celtique.

Sus bases bibliográficas se ven aumentadas considerablemente, sumando a las clásicas obras de Belloguet (1858), Reinach $(1892,1910)$ o Bertrand (1894; 1889), las de Déchelette (1911-1914), Fustel de Coulanges (1888), sin dejar de ser obra de referencia continua la de d'Arbois (1889) al que sigue en el análisis lingüístico e interpretación de las fuentes.

Las ideas de d'Arbois y Déchelette sobre el concepto de celta y su formación influirán decisivamente en él. El termino celta implica una unión lingüística que distingue un carácter, lo que determina la cultura, la etnicidad y, por tanto la religión. Así se definiría la constitución de un empire celtique, muy basado en cuestión de fuentes, en los escritos de Tito Livio.

Sin embargo este libro tiene un punto de madurez que lo distancia abismalmente del primero. Aquí el autor no se conforma con los resultados de su investigación, consciente de la limitación y el sesgo que suponen los medios sobre los que recomponer el puzzle céltico. Así, añade un apartado de conclusiones muy duro y crítico que, en parte anticipa muchas de las actuales dudas y carencias que hoy reconocemos. El sesgo de la realidad arqueológica, filológica o de los textos clásicos, la reducida muestra que supone el mundo céltico irlandés, o el riesgo que corremos al considerar como fases sucesivas las diferentes visiones que de estos pueblos han tenido quien escribía sobre ellos, eran puntos flacos que veía necesario reconsiderar. Tampoco la reconstrucción filológica es muy fiable y reconoce que depende en gran parte del estudio de los dialectos de las Islas Británicas y su comparación con los restos epigráficos o numismáticos.

Esta obra, reescrita en plena Guerra Mundial, refleja un sentimiento que no hará mucha mella en

T. P., 58, n. ${ }^{\circ} 2,2001$ 
los investigadores posteriores, más apegados al nacionalismo reinante, hasta bastante más tarde. Sin embargo hoy sería un hombre de actualidad, y su crítica histórica de una tremenda franqueza, cuando dice (Dottin, 1915: 271): "Los hombres de prolífica imaginación, que frecuentemente se obsesionan con la idea de una raza céltica no sabrían encontrar en el caso de los celtas de laAntigüedad un pretexto suficiente para sus investigaciones. ¿Pueden probar a definir lo que pertenecería a los pueblos célticos en el conjunto de pueblos modernos que habitan hoy en países donde antaño habitaron los celtas? Se debería estudiar ese punto de vista no solo con los franceses, sino con los alemanes del sur, austríacos, italianos de la cuenca del Po y los mismos españoles".

Es, probablemente, el primer investigador sobre el tema céltico que reconoce una implicación social y política, aunque sea somera, en la forma de hacer literatura sobre el tema. La separación que se comenzaba con la aparición de los primeros arqueólogos desde el anticuarismo y la instauración del método se comienzan a deshacer de la pátina del romanticismo épico, en el que el arqueólogo es un burgués acomodado o un noble excéntrico al que le gustan las antiguas odiseas y el dulzor evocador de repensar esos mundos de leyenda.

Es muy curioso ver cómo se unen todavía en el pensamiento de Dottin los conceptos paneuropeistas de la nación céltica o las inferencias de las evidencias sacadas de las fuentes del mundo clásico o el recurrente modelo irlandés, con la incipiente duda sobre la validez real de estos planteamientos y la aplicación del método histórico a laArqueología.

En conclusión, por una parte hay que reivindicar la gran importancia de los estudios de d'Arbois como sistematizador y generador de las bases argumentales, tanto de la teoría étnico-cultural, que más tarde desarrollaría Kossinna, como de la interpretación de las estructuras sociales y políticas de la céltica, tomadas de los modelos creados por los filólogos y arqueólogos alemanes para la Germania. Con él, la figura de Déchelette, como gran difusor de las teorías y argumentos de d'Arbois, así como de numerosos planteamientos propios, en uno de los manuales de arqueología más consultados en este siglo.

\section{EL CASO INGLÉS}

La tradición inglesa constituye el otro gran pilar de la arqueología céltica en Europa durante el pe- riodo que tratamos, pero de forma paralela a la francesa o alemana. Como ya habíamos comentado, la revolución arqueológica fue marcada por la aparición en este país de la obra de John Lubbock Prehistoric Times (1865), la más influyente durante todo este tiempo en el panorama anglosajón y según afirma, algo exageradamente, Trigger (1992: 114): “...sin lugar a dudas el libro de arqueología más influyente de todo el siglo XIX".

Sin embargo el evolucionismo impenitente de Lubbock no fue un foco real de influencia a la hora de reflejarse en los textos fuera del mundo anglosajón, aunque sí quedaron ciertas ideas como la de la gradación de los pueblos primitivos o las series tipológicas determinadas por estadios evolutivos que calaron en la doctrina difusionista de corte británico.

El mundo de la arqueología céltica también se introduciría en esta corriente pronto, ya que estos también estarán en el grupo de los célticos, esto es, de aquellos países europeos que basan sus raíces étnicas en la tradición celta. Aunque de forma algo controvertida, ya que los conflictos con la invasión irlandesa y la defensa de una identidad anglo-sajona suponían ciertas contradicciones, existió un monopolio celta por parte de los ingleses (principalmente) contra otros celtismos regionales como el irlandés (reivindicaciones argumentadas sobre ciclos épicos como el de CúChulain) y el escocés (etnicidad de los pictos y pueblos caledonios).

Los ingleses conocían bien las excavaciones en Centroeuropa y asumieron los sistemas clasificatorios y las tablas cronológicas relativamente pronto aunque, por supuesto, adaptándolas rápidamente a su particular caso. Una de las primeras y más completas de las síntesis sobre la Edad del Hierro en Europa tratada por ingleses incluyendo tablas cronológicas fue la Guide to Early Iron Age Antiquities del Museo Británico de 1925.

La actitud mantenida desde la academia inglesa (británica en general) será bastante alejada de lo que hemos visto hasta ahora en el mundo francés. Se contemplan los pueblos célticos como un conjunto de tribus actuando a veces de forma conjunta, descartando el concepto de la "nación celta" y por supuesto del "imperio celta". Quizá por eso la mayoría de los textos hacen poca referencia a los trabajos de los franceses, prefiriendo centrarse en los escritores autóctonos. Tan sólo uno de estos autores es nombrado en estos trabajos y es Salomón Reinach. Sus planteamientos no entrarían en conflicto con los planteamientos británicos de preemi- 
nencia cultural y racial anglosajona en las Islas y apoyan un difusionismo mediterráneo muy de moda entonces como explicación de los focos de origen de los adelantos técnicos.

Para ellos, los pueblos antiguos de Europa serán básicamente Illyrios, Ligures e Iberos, pero pronto aparecen los celtas en ese panorama. Su aparición en los textos de Herodoto, Avieno, Hecateo, Cesar o Livio, los lleva hacia los siglos VII y VI, pero ya antes se admite una formación previa de estos grupos en el centro de Europa. Su carácter será difícil, violento y bárbaro, con una tendencia a expandirse y a hacer razzias sistemáticas.

Entre los más importantes autores de esta ortodoxia inglesa estuvieron Sir William Ridgeway, Clement Reid, o Jose María de Navarro. Este último fue profesor en Cambridge y un gran especialista en mundo céltico, tanto centroeuropeo como británico. Sus aportaciones estuvieron vinculadas al campo de la armamentística, arte y las explicaciones de las migraciones y movimientos célticos (Navarro, 1928), así como sus orígenes como cultura (Navarro, 1936). Sin embargo no se aportaba nada nuevo al concepto tradicional de celtismo y se recurrían una y otra vez a los mismos argumentos y textos antiguos. Quizá lo que si comenzaron a hacer los británicos con asiduidad es comparar los resultados de excavaciones con lo escrito en las fuentes e intentar una contrastación.

Otro interesante aspecto de la escuela inglesa será la necesidad de crear elementos diferenciadores del continente pero aglutinadores con respecto a las Islas. Para ellos serán los Britones los célticos de su zona y generarán toda una imagen de rudeza cargada de simbolismo medievalista. El peso de los ciclos legendarios del medioevo y la asunción de que estos son remanentes de la antigüedad "céltica" llevan en muchos casos a generar una imagen conceptual mezclada, llena de elementos heterogéneos. La caracterización de estos pueblos, primeros pobladores de la húmedaAlbión, tendrá un claro corte antropológico, respondiendo a las expectativas de los pueblos escandinavos. Se definirán para ello dos tipos de galo-celtas, los de la zona sur, oscuros (dark haired) (VV.AA., 1925: 6-10) braquicéfalos y de corta estatura; y los que compondrían en origen la población británica, que serían altos rubios y de ojos claros, descendientes de aquellos venidos de las zonas nórdicas y Germania.

Curiosamente este interés por el tipo físico nórdico contrasta con una fascinación por el modelo cultural mediterráneo, componiendo unas interesantes mezclas. Para Ridgeway los aqueos serían fisicamente nórdicos y se identifican como celtas, así como para Reinach se pueden intuir relaciones con las costas británicas de frigios y fenicios desde el 850 a. C.

La argumentación inglesa sobre sus raíces culturales célticas se fortalece con la reconstrucción de la invasión de la isla por los britones y goidélicos, ambos pueblos muy celtas, y que desplazan a los Cruithne o pictos (pueblo de los pintados), que serían los primeros habitantes de la isla y los relegados a Gales y Escocia. Así, distinguirían también a los diferentes tipos de gentes de las islas. Los de apariencia oscura y baja serían "sangre" de los primeros pobladores, mientras que los altos y claros serían los victoriosos celtas. Más tarde llegarían los belgas, más germanizados y asentados tan sólo en algunas partes de la costa sur de Inglaterra.

Estos planteamientos se vinieron forjando durante todo el siglo XIX y cristalizarían en trabajos como los de Sir John Myres o Sir Arthur Evans, aunque los anticuarios ya se habían centrado en los vestigios célticos mucho antes, y componian una tradición amplia con una literatura propia. Es el caso del anticuario William Stukeley, que ya en su obra hacia 1723 denomina muchos de los monumentos antiguos conocidos entonces como "celtas", o de John Williams, y sus trabajos sobre fortificaciones y asentamientos del año 1777.

Las instituciones de investigación tomaron un papel principal en los trabajos sobre la Edad del Hierro, destacando el British Museum y sus conservadores de las colecciones protohistóricas y de entre ellos August Wollaston Franks, estudioso de las colecciones de la Edad del Hierro. En 1863 editó una obra ilustrada sobre los fondos del museo de este periodo, refiriéndose a ellos como del periodo La Tène tardío. Otro interesante y muy prolífico investigador en esta misma línea, también vinculado a este museo será $C$. Hawkes, cuyo interés profundo por la investigación de la Edad del Hierro le llevó a escribir numerosas obras y realizar multitud de excavaciones. Pertenecerá a una época de total relanzamiento de la disciplina, que corresponderá a la década de los treinta. En este periodo se recurre a los primeros estudios de Myres y principalmente de Evans, quien en 1890 había articulado, sobre la base de los hallazgos en la necrópolis de Ayles, o los descubrimientos de Welwyn o Swarling, un modelo de difusión de las culturas celtas en relación con la costa norte de Europa y los

T. P., 58, n. ${ }^{\circ} 2,2001$ 
pueblos antiguos que ahí habitaban, especialmente los belgas. Para él existía una posibilidad importante de poder inferir una correspondencia entre los datos de las fuentes sobre grupos étnicos antiguos y "culturas" arqueológicas, idea bastante difundida en el panorama europeo. Esto le lleva a asimilar, por ejemplo, la invasión belga con la llamada "cultura de Aylesford-Swarling", basándose en las monedas recogidas en el yacimiento adscribibles a los galo-belgas. Así desarrolla una preocupación por reconocer la adscripción geográfica de ciertos asentamientos y "culturas", traspasándola a sus discípulos, como pasará con Childe.

Sin embargo existe una figura destacada entre la investigación en Inglaterra durante estos años, saliéndose de lo común en todos los aspectos. Sus obras tuvieron una gran repercusión por su gran capacidad de síntesis, su visión amplia y profunda de Europa y su corpus teórico novedoso y bien desarrollado. Este hombre excepcional, influido por los más importantes personajes de su tiempo y creador de una línea de pensamiento tras él será Vere Gordon Childe.

Sus estudios son una mezcla de tinte materialista bajo la influencia de la escuela de Ravdonikas, el difusionismo, muy influido por la obra de Montelius (1899) y los planteamientos de Kossinna. Para Trigger (1980) quizá una de las tendencias más básicas en la obra de Childe sea el corte historicista de Von Ranke, aunque no parece ser una opinión compartida con otros investigadores (Green, 1981; McNair, 1980; Piggott, 1958) y tampoco sea algo claramente palpable en sus escritos.

Sus interpretaciones sobre la Inglaterra céltica serán amplias y bien documentadas, siendo partidario de establecer procesos de larga duración en los que las transformaciones sociales van a venir producidas por aportes e incorporaciones de elementos exógenos a los grupos autóctonos. Defiende la continuidad de grupos de jefaturas, afectados por elementos externos, produciendo una serie de cambios en la situación de desigualdad social que va a generar una serie de cambios sociales. Así, desde las "culturas de los túmulos" de Wessex, hasta la última oleada de los belgas, que traerán la tradición de las producciones cerámicas con pie alto y el rito teutón de la incineración, se van sucediendo una serie de contactos transformadores que fortalecen las jefaturas de tipo guerrero. Tras la de los urnfields aparecerán unos primeros celtas, que ya habían tenido contactos precedentes, y que se asientan en la isla trayendo la cultura de La Tène.
Más tarde los germanos, celtas goidélicos y pictos entran en la Isla y terminan de conformar el mapa de los pueblos célticos británicos (Childe, 1940).

Entre los investigadores anglosajones dejará honda huella, especialmente en Stuart Piggott y Sir Mortimer Wheeler, así como en toda una generación que tras la II Guerra Mundial despierta a sus trabajos traducidos rápidamente al francés, alemán y algo más tardíamente al español. En nuestro caso solo hacia la década de los sesenta podemos observar una verdadera influencia de su obra en España, aunque muchas de sus interpretaciones sobre grandes procesos de la antigüedad (como el origen de la domesticación, o la metalurgia, etc.) eran tímidamente conocidas.

Pero ya a principios de los años veinte la influencia de Childe se hacía notar en sus colegas, como por ejemplo en la obra del ya nombrado Burkitt (1926), profesor de Arqueología de Cambridge, al cual llegan muchas de las influencias extranjeras por medio de él. La herencia inglesa en el continente americano será claramente palpable y su comunicación muy fluida.

La escuela de Childe será la más internacional de todas y la mejor conocida en Europa, llegando a España a través de lecturas con una trascendencia teórica y metodológica crucial (Childe, 1922, 1926, 1933), desarrollando conceptos como el de la etnicidad aria. Serán conocidas aquí bastante tarde sus teorías sobre el mundo indoeuropeo, los planteamientos de la difusión de esta cultura y sus vínculos con poblaciones actuales, muy influenciadas en sus primeros momentos por la escuela alemana. Los estudios sobre la protohistoria de Escocia, las interpretaciones sobre loshillforts, la prehistoria de Centroeuropa o la difusión de las interpretaciones de la escuela ex oriente lux, serán algunas de sus principales aportaciones a laArqueología europea.

Pocas serán las relaciones entre Inglaterra y España, tan solo reducidas a vínculos personales entre investigadores y relacionados en cierta forma con los intereses políticos. Pocos arqueólogos ingleses trabajarán en España y viceversa y no comenzará a haber un verdadero interés por las corrientes inglesas hasta muy recientemente.

\section{CONCLUSIONES}

La construcción de este paradigma, definido como étnico-cultural, extiende sus prolongaciones desde aquellos momentos de auge de entreguerras, 
hasta los tenues pero relevantes restos remanentes en nuestros días. Su construcción corresponde a la creación de una base interpretativa sobre la que realizar laArqueología derivada de la escuela histórico/cultural de Viena.

Implicaría, por tanto, la asunción de que a través del dato arqueológico tratado mediante técnicas tipológicas se puede definir una"cultura arqueológica", que a su vez corresponde con una cultura contemporánea y, por lo tanto a una etnia. Esta relación se establece en virtud de asumir que, en la definición de una cultura están incluidos valores de carácter que la representan de forma étnica.Así, una determinada etnia sólo puede producir un tipo de cultura y esta es reconocible por lo tanto a través de un registro arqueológico específico. Esto incluiría que, en su camino hacia la "perfección" (el Estado cristiano germánico en términos hegelianos), cada grupo está dotado de forma natural de diferentes capacidades para ocupar un lugar en la pirámide cultural (cuya cúspide es elEstado "germánico"o "céltico", dependiendo de las interpretaciones). Los modelos coloniales que habían afectado a las interpretaciones sobre la expansión del Neolítico, Calcolítico, Edades del Bronce o Hierro, dentro de la explicación difusionista, encajaban de maravilla con las necesidades del celtismo. Las condiciones de ese modelo implicaban esa "cultura común" de la que hemos hablado, entendiéndola como formas sociales, religiosas e ideológicas comunes a cada pueblo "colonizador”. Fruto de esta tradición y concepción de la Arqueología será laArqueología del dato positivo, la definición de "culturas arqueológicas" y su referenciación a yacimientos epónimos. Este mismo planteamiento permite paralelizar de forma directa evidencias arqueológicas sin frontera en el tiempo o espacio, simplemente atendiendo a no salirse de la "zona de influencia cultural". Todavía hoy se justifica la adscripción de formas sociales y sus correspondientes proyecciones espaciales, paisajísticas o habitacionales, al ser considerado un "rasgo de carácter".

De toda esta conjunción de elementos quedan la adopción de nuevos conceptos como"cultura", "paradigma étnico", o el método Kossinna, muy seguido y practicado por los profesores alemanes de los primeros años del siglo XX y hasta la Segunda Guerra Mundial. Merhart, Jankuhn, Schmidt o Menguin entre otros muchos, utilizaron este método, aplicando laArqueología de los asentamientos, las técnicas paleoantropológicas y sus argumentaciones, así como la integración de estas en sistemas étnico-cul- turales y transmitiéndolo a sus discípulos. Serán los primeros prehistoriadores y los que transmitirán el término como definitorio de una disciplina que estudia este período con ayuda de las técnicas arqueológicas en España ya en los años 20 y 30.

La escuela histórico cultural deViena será la que marque el contenido de la Arqueología española prácticamente hasta nuestros días. Las críticas a Kossinna serán muchas y sus teorías se verán desarrolladas y depuradas por otros como Jürgen Eggers (1951) o Herbert Jankuhn (1943, 1956), que sí seguirán aceptando los métodos pero prescindiendo en todo o en parte del paradigma étnico (Härke, 1991: 188). En España este academicismo monoteórico, sumado a las condiciones políticas de postguerra, propiciarán una parálisis de la dialéctica teórica, no reanudada hasta los tímidos comienzos de la apertura mental al mundo anglosajón hacia mediados de los ochenta. Pero este fenómeno se produjo igualmente en el terreno de la academia germana, donde los estudios de Härke $(1989,1991)$ revelan una total parálisis en el aspecto teórico e interpretativo durante el último medio siglo y especialmente en los veinte últimos años. Esto puede ser debido a que el historicismo tradicional basa sus líneas argumentales en el dato positivo y su subsistencia como disciplina en el principio de autoridad, lo que elimina, en gran medida, el proceso dialéctico y la posibilidad de regeneración teórica.

La academia inglesa, por su conformación y su distanciamiento histórico de España, que se encontraba tradicionalmente más cercana al eje francoalemán, no ha llegado a tener una influencia real y palpable hasta bien entrada la segunda mitad de este siglo. Sí nos llegará, una vez más bajo el prisma de la interpretación francesa, el elemento céltico anglosajón, y algunas referencias a Myres o Evans y algún trabajo, ya muy tarde, de Childe.

Hoy, la revitalización de los estudios sobre la cuestión céltica trae también una reactivación de elementos generados en estos momentos. Los planteamientos creados por el paradigma étnico-cultural van a servir de fondo argumental en estudios hoy en día que, aunque ya no son competencia de este estudio, esperamos poder seguir trabajando. Este fenómeno es parte del proceso mismo de generación de la disciplina arqueológica en nuestro país, cuya continuidad es palpable. Pese a la revolución teórica de los años 80 las cargas académicas tradicionales son definitivas para una importante parte de la investigación en España, en muchos casos incluso, sin ser plenamente conscientes de ello. 


\section{BIBLIOGRAFÍA}

D'Arbois de Jubainville, H. (1871): “Glosaire gaulois". Revue Celtique, 1: 457-459.

- (1889): Premiers habitants de l'Europe. Ernst Thurin. París.

- (1893-1894): "Les celtes en l'Espagne". Revue Celtique 14: 357-395; 15: 1-61.

- (1902): "Principaux auters à consulter pour l'histoire des celtes". Cours de littérature celtique, 12.

- (1904): Les celtes dépuis les temps plus anciens jusqu'à l'an 100 avant nôtre ère. Durand. París.

- (1981): El ciclo mitológico irlandés y la mitología céltica. Taurus. Barcelona, $1^{\text {a }}$ ed. 1912.

Belloguet, R. (1858): Ethnogénie gaulois. Picard. París.

BERTRAND, A. (1889): Archéologie celtique et gaulois. Ernest Leroux. París.

Bertrand, A. y Reinach, S. (1894): Les celtes dans les vallées du Pô et du Danube. Durand. París

Braidwood, R. J. (1958): "Vere Gordon Childe". American Anthropologist, 60: 733-736.

BuchanAn, G. (1582): Rerum Scoticarum Historia. Alexander Arbuthnet. Edimburgo.

BuRKITT, M.C. (1926): Our early ancestors: an introductory study of Mesolithic, Neolithic and CopperAge cultures in Europe and adjacent regions. Cambridge University Press. Cambridge.

Bywetrag, M.S. (1994): De l'art roman à la Prehistoire des sociétés locales à l'Institut, itinéraires de Joseph Déchelette. Lugd. Lyon.

Childe, G.V. (1922): “The present states of Archaeological studies in Central Europe". MAN, 22: 12-34.

- (1925): The dawn of the european civilisation. Kegan, P. Londres.

- (1926): The Aryans: A study of Indo-european origins. P. Kegan. Londres.

- (1933): "Races, peoples and cultures in prehistoric Europe". History, 18: 193-203. Londres.

- (1940): Prehistoric Communities of the British Isles. Chambers. Londres.

Collis, J. (1997): "Celtic Myths". Antiquity, 71: 195-201.

- (1994): "The Iron Age". Building of the past: a celebrating of 150 years of the Royal Anthropological Institute. B. Vyaev. Londres: 123-148.

DANiEL, G.E. (1950): A hundred years of Archaeology. Duckworth. Londres.

DéChelette, J. (1904): Les fouilles de Mont Beuvray de 1897-1901. Protat Fréres. París.

- (1911-1914): Manuel d'archéologie préhistorique, celtique et galo-romaine I-IV. Alphonse Picard. París.

- (1912): Les fouilles du marquis de Cerralbo. Academie des Inscriptions et Belles-Lettres. París.

Desjardins, H. (1871): Géographie Historique et Administrative de la Gaule Romaine. Felix Alcan. París.

- (1883): Géographie de la Gaule d'aprés la Table de Peutinger. Académie Française. París.
DíAZ-ANDREU, M. (1995): “Arquéologos españoles enAlemania en el primer tercio del siglo XX. Los becarios de la Junta para laAmpliación de Estudios e Investigaciones Científicas". Madrider Mitteilungen, 32: 79-89.

- (1996): “Arquéologos españoles enAlemania en el primer tercio del siglo XX. Los becarios de la Junta para la Ampliación de Estudios e Investigaciones Científicas". Madrider Mitteilungen, 37: 205-224.

Dotтin, G. (1906): Manuel Celtique. Université du Rennes. Rennes.

- (1915):Manuel pour servir à l'étude de l'antiquitéceltique. Champión. París.

EGGERS, H.J. (1950): "Die vergleichende geographisch-kartographische Methode in der Urgeschichtsforschung". Archaeologia Geographica 1: 1-3.

- (1951): "Der römische Import im freien Germanien". Atlas der Urgeschichte 1, Museum für Völkerkunde und Vorgeschichte.

Evans, A. J. (1850): "On the date of British coins". The Numismatic Chronicle and Journal of the Numismatic Society, 12:127-137.

- (1890): "On a Late Celtic Urn-Field at Aylesford, Kent, and on the Gaulish, Illyro-Italic and Classical connexions of the forms of pottery and bronze-work there discovered". Archaeologia, 52: 315-388.

FIck, M. (1873): Die ehemalinge Spracheinheit der Indogermanen Europas. Berlín.

Fustel DE COULANGES, D.J. (1888): La cité antique: étude sur le culte, le droite, les institutions de la Grèce et de Roma. Ciges. París.

Gran-Aymerich, E. (1998): Naissance de l'archéologie moderne: 1798-1945. UAI. París.

Green, S. (1981): Prehistorian: a Biography of V.Gordon Childe. Moonraker Press. Bradfor-on-Avon.

HÁrKe, H. (1989): "The Unkel symposia: the beginings of a debate in West German archaeology?" Current Anthropology. 30: 406-10.

- (1991): "All quiet on the western front? Paradigms, methods and approaches in west german archaeology". ArchaeologicalTheory in Europe. Routledge. London: 187-222.

Hawkwes, C. (1931): "Hillforts". Antiquity, V: 60-97.

- (1948): "From Bronze Age to Iron Age: Middle Europe, Italy and the North and West". Proceedings of the British Academy, XIV: 196-218.

JACOBSTHAL, P. (1929): Die Bronzeschnabelkannen: Ein beitrag zur geschichte des vorremischen imports nordlich der alpen. A Frank. Berlin.

- (1944): Early celtic art. Clarendon Press. Oxford.

James, S. (1999): The Atlantic Celts: Ancient People or Modern Invention. British Museum Press. Londres.

JANKUHN, H. (1937): Haithabu: Eine germanische Stadt der Frühzeit. Wachholtz. Neumünster.

- (1943): DieAusgrabungen in Haithabu (1937-1939): Vorläufiger Grabungsbericht. Ahnenerbe. BerlinDahlem. 
- (1956): Haithabu: Ein Handelsplatz der Wikingerzeit. Wachholtz. Neumünster.

Kelly, F. (1988): A guide to early Irish law. DIAS. Dublin.

KosSAK, G. (1992): "Prehistoric Archaeology in Germany: its History and Current Situation". Norwegian Archaeological Review, 25 (2): 73-109.

Kossinna, G. (1911): Zur herkunft der germanen, zur methode der siedlungsarchäologie. Mannus Bibliothek, 6 .

- (1921): Die Indogermanen (Ein abris. Das Indogermaniesche Urvolk). Curt Kabitzsch. Leipzig.

- (1941): Die deutche Vorgechichte (eine hervorragend nationale Wissenschaft). Curt Kabitzsch. Leipzig.

Lhuyd, E. (1707): Archaeologia Britannica, I. Theater. Oxford.

López JimÉnez, O. (1999): “De Powell a James: 41 años de sueños célticos". ArqueoWeb, 1(1) www.ucm.es/info/ arqueoweb. Madrid.

Lubbock, J (1865): Pre-historic times, as illustrated by ancient remains, and the manners and customs of modern savages. Williams and Norgate. Londres.

LuCAs, A.T. (1989): Cattle in ancient Ireland. Boethius. Kilkenny.

McNAIR, B. (1980): The method and theory of V.G. Childe: economic, social and cultural interpretation of History. Edimburgh University Press. Edimburgo.

Menghin, O. (1931-1940): Welgeschichte der Steinzeit. Shlutz. Viena.

Montelius, O. (1899): Der Orient und Europa. Königl. Estocolmo.

- (1903): Die typologische methode: die älteren Kulturperioden in Orient und Europa. Selbstverlag. Estocolmo.

Morgan, L.H. (1877): Ancient Society. Holt. Nueva York.

Mortillet, G. de (1870): Formation de la nation française. Felix Alcan. París

- (1883): Le prehistorique antiquite de l'homme. Bibliotheque des Sciences Contemporaines. Reinwald. París.

Navarro, J.M. de (1928): "The comming of the Celts". Cambridge Ancient History, VII: 41-74.

- (1936): "A survey of research on an Early Phase of celtic culture". Proceedings of the BritishAcademy, XXII: 297-341.

OBERMAIER, H. (1932): El hombre prehistórico y los orígenes de la humanidad. Revista de Occidente. Madrid.

Obermaier, H. y Bernhart, J. (1931): Urgechichte der Menschheit. Herder \& Co. Freiburg.

PATterson, N. (1994): Cattle lords and clansmen: the social structure of early Ireland. University of Notre Dame Press. Notre Dame.

PARE, C. (1991): "Fürtensitze, celts and the mediterranean world: developments in west hallstatt culture in the $6^{\text {th }}$ and $5^{\text {th }}$ centuries b.C." Proceedings of the Prehistoric Society, 52 (2): 183-202.

PAuli, C. (1891): "Die veneter und ihre Schiftdenkmaeler". Altitalische Studien, III.
Piggott, S. (1958): "Vere Gordon Childe, 1892-1957". Proceedings of the British Academy, 44: 305-312.

RATZEL, F. (1896-1898): The History of Mankind. McMillan. Londres. Trad. A. Butler.

ReINACH, S. (1892): "Le Etain Celtique". L'Anthropologie, 3: 276-281. París.

- (1893): Le mirage oriental. G. Masson. París.

- (1910): Répertoire de reliefs gauls et romains. G. Masson.

ReINECKE, P. (1902): "Zur Kenntnis der Latène-Denkmäler der Zone norwärts der Alpen". Festschrift zur Feier des fünfzigjähringen Bestehens des RGZ museums zu Mainz. Mainz.

- (1906-7): "Die originalaltertümer im RGZ Museum in Mainz". Mainz Zeitung, 2: 40-69.

- (1911): Mainzer aufsätze zur chronologie der bronze - und eisenzeit. Habelt. Bonn.

Renfrew, C. (1973): Before Civilization: The Radiocarbon Revolution and Prehistoric Europe. Jonathan Cape. Londres.

Rodenwaldt, G. (1933): Arte Clásico: Grecia y Roma. Labor. Barcelona.

Ruiz-Gálvez Priego, M.L. (1997): "En busca del hogar de Breogán". Celtas y celtíberos. Realidad o leyenda. Unión Cultural Arqueológica. Madrid: 37-51.

Ruiz Zapatero, G. (1997): "La noción de celtas y su empleo académico y político". Celtas y Celtíberos: Realidad o Leyenda. Unión Cultural Arqueológica. Madrid: 17-36.

SANDERSON, S.K. (1992): Social Evolutionism: a critical history. Mass: Blackwells. Cambridge.

Saussure, F. de (1871): Mémoire sur le système primitive des voyelles. Marat. Burdeos.

Schade, M. (1856): Altdeutsches Wärterbuch. Berlín.

SchmidT, H. (1933): "Die Fürstengräber von Klein Glein in Steiermark". Praehistorische Zeitschrift, 24: 219282.

SklcúAv, K. (1983): Archaeology in Central Europe: the first 500 years. Leicester.

Stocking, G.W. (1987): Victorian Anthropology. Free Press. Nueva York.

Thierry, A. (1828): Histoire des gaulois. Didier et Cie. París.

Trigger, B. (1980): Gordon Childe: Revolutions in Archaeology. Thames \& Hudson. Londres.

- (1984): "Alternative Archaeologies: nationalist, colonialist, imperialist". Mann, 19: 355-370.

- (1992): Historia del pensamiento arqueológico. Crítica. Barcelona.

TYlor, E.B. (1871): Primitive culture. Murray. Londres.

VIRCHOW, R. (1870): Slavic burgwall. H. Kromayer und B. Heisenberg. Heidelberg.

VV.AA. (1925): Guide to Early Iron Age antiquities. British Museum. Londres.

Woorsae, J.J.A. (1849): The Primeval Antiquities of Denmark. Thoms Parker. Londres. W.J. Parker, traducción.

T. P., 58, n. ${ }^{\circ} 2,2001$ 